\title{
Influence of surface reflectivity on radiation in the Antarctic environment
}

I. Smolskaia, S. Wuttke, G. Seckmeyer, K. Michael

I. Smolskaia, S. Wuttke, G. Seckmeyer, K. Michael, "Influence of surface reflectivity on radiation in the Antarctic environment," Proc. SPIE 6362, Remote Sensing of Clouds and the Atmosphere XI, 63620V (11 October 2006); doi: 10.1117/12.689693

SPIE. Event: SPIE Remote Sensing, 2006, Stockholm, Sweden 


\title{
Influence of surface reflectivity on radiation in the Antarctic environment
}

\author{
Smolskaia I..$^{{ }^{*}}$, Wuttke S. ${ }^{\mathrm{b}}$, Seckmeyer G. ${ }^{\mathrm{a}}$ and K. Michael ${ }^{\mathrm{c}}$ \\ ${ }^{a}$ Inst. of Meteorologie and Climatology, Leibniz Univ. Hannover, Herrenhaeuser Str. 2, D-30419 \\ Hannover, Germany; \\ ${ }^{\mathrm{b}}$ Alfred Wegener Institute for Polar and Marine Research, Am Handelshafen 12, 27570 \\ Bremerhaven, Germany; \\ ${ }^{c}$ Inst. of Antarctic and Southern Ocean Studies, Univ. of Tasmania, GPO Box 252-77, Hobart, TAS \\ 7001, Australia
}

\begin{abstract}
We demonstrate the importance of surface reflectivity for the radiation field in polar regions by a combination of measurements and radiative transfer calculations. Results from measurements of spectral albedo, radiance and irradiance from 280 to $1050 \mathrm{~nm}$ at German Neumayer Station in Antarctica in summer 2003/2004 as well as measurements of UV irradiance during summer 1997/1998 at Australian Davis Station, Antarctica are presented. The impact of surface albedo inhomogeneity is investigated by 3-D Monte Carlo modelling. We found that high surface reflectivity in the ultraviolet and visible parts of the spectrum due to the snow covered surface in Antarctica modifies the radiation field considerably compared to mid-latitudes. A change of the spectral reflectivity, which happens as a consequence of climate change will have a large impact in the radiation properties in polar regions and vice versa.
\end{abstract}

Keywords: radiation, surface reflectivity, Antarctica, UV, Monte Carlo, spectral albedo, climate change

\section{INTRODUCTION}

The energy budget of the Antarctic continent is strongly influenced by the surface albedo, which is defined as the ratio of reflected to incident irradiance. The averaged surface albedo (300 to $3000 \mathrm{~nm}$ ) of the Antarctic ice shelves is around $0.83^{1}$. A change in prevailing climatic conditions can enhance feedback mechanisms, such as the ice-albedo feedback, which can be triggered by a change in temperature. Depending on the sign of temperature change, the ice-albedofeedback has contrary effects: (1) A rise in temperature leads to an enhancement in snow and sea ice melt, which in turn causes the surface albedo to decrease. More radiation is absorbed increasing the energy budget and leading to a further rise in temperature. (2) A decrease in temperature leads to a greater production in sea ice, which in turn increases the surface albedo. Less radiation is absorbed decreasing the energy budget and leading to a further cooling.

Due to the detected rise in temperature over the Antarctic Peninsula and sub-Antarctic ${ }^{2}$, the ice-albedo-feedback mechanism under (1) is induced there. Regional warming in the sub-Antarctic region is also linked to higher precipitation in the Antarctic ${ }^{3}$. Depending on the temperature regime, precipitation in Antarctica will fall in the form of rain (most likely over the Antarctic Peninsula in summer) or snow (most likely over the Antarctic continent). More freshly fallen snow increases the albedo so that the feedback mechanism (2) is initiated over the Antarctic continent. These two contradictory processes need to be considered when investigating climate related albedo effects in Antarctica.

Spectral albedo measurements previously conducted in Antarctica ${ }^{4}$ yield a dependence of albedo on wavelength, snow grain size and solar zenith angle. These measurements have been performed with a filter radiometer with a resolution of about $20 \mathrm{~nm}$. A uniform high albedo with 0.96 to 0.98 is reported across the UV and visible, nearly independent of snow grain size and solar zenith angle. The albedo in the near infrared is lower, dropping below 0.15 in the strong absorption bands of ice at 1500 and $2000 \mathrm{~nm}$.

It has been observed by several authors ${ }^{5,6,7}$ that the high albedo of a snow covered surface, especially in the UV and visible, has a large effect on the downwelling radiation due to multiple reflections between the ground and the scattering

Remote Sensing of Clouds and the Atmosphere XI, edited by James R. Slusser, Klaus Schäfer, Adolfo Comerón, Proc. of SPIE Vol. 6362, 63620V, (2006) · 0277-786X/06/\$15 - doi: 10.1117/12.689693 
atmosphere. Model calculations of ultraviolet irradiance for cloudless sky ${ }^{8}$ show enhancements in irradiance levels of nearly $50 \%$ at $320 \mathrm{~nm}$ for a snow covered surface in comparison with snow free conditions. The enhancement is much larger when the sky is cloudy than when it is clear, because of the increased atmospheric backscattering due to clouds. A number of previous studies investigate the combined effect of surface albedo and clouds on UV irradiance:

- McKenzie et al. (1998) ${ }^{5}$ : Experimental studies have shown an increase in UV irradiance of approximately $40 \%$ due to a snow albedo of 0.8 . The enhancement in UV irradiance levels over a snow covered surface compared to a snow free surface amounts to $70 \%$ when a cloud cover is present.

- Kylling et al. (2000) ${ }^{6}$ : Snow cover at Tromsö, Norway, increases the erythemal UV dose by more than $20 \%$. The maximum increase of a daily dose compared to snow free conditions is $63 \%$ for a cloudy day.

- Nichol et al. (2003) $)^{9}$ : The moderation of cloud reduction on UV irradiance in the Antarctic due to a high surface albedo is investigated. Compared to a cloudless case and a low surface albedo (0.05) a reduction of $40 \%$ in UV irradiance for cloudy conditions results. Increasing the surface albedo to 0.8 and 0.96 lead only to an attenuation by $20 \%$ and $10 \%$, respectively.

When the snow cover is not uniform, the impact of the snow distribution has been analysed, based on three-dimensional (3-D) models, like SH-DOM ${ }^{10}$, or Monte Carlo ${ }^{11,12,13}$. All authors agree that areas more than $50 \mathrm{~km}$ from the observation site can still contribute to a few percent of the enhancement. Measurements near the coast line between ocean and snow covered terrain ${ }^{14}$ have been discussed by Mayer and Degünther ${ }^{16}$ and reconciled with a modelling study by Smolskaia ${ }^{13}$.

\section{ANTARCTIC MEASUREMENTS}

Radiation measurements have been performed in Antarctica at two different stations during two different seasons. The first campaign took place near the Australian Davis Station, East Antarctica $\left(68.58^{\circ} \mathrm{S}, 77.97^{\circ} \mathrm{E}\right)$ in the austral summer $1997 / 1998^{14}$. The second campaign was performed at the German Antarctic Neumayer Station situated on the Ekström Ice Shelf on the Weddell Sea $\left(70^{\circ} 39^{\prime} \mathrm{S}, 8^{\circ} 15^{\prime} \mathrm{W}\right)$ in the season $2003 / 04^{15}$.

\subsection{Irradiance measurements at Davis Station}

The measurements at Davis Station were designed to assist in the validation of modelled horizontal variations in surface irradiance resulting from step changes in surface albedo ${ }^{13}$. The changes in UV irradiance over water and fast ice as a function of a distance from the ice edge were measured along transects perpendicular to the ice edge using two Solar Light 501A UV Biometers and a Macam SR9910 17 double grating spectroradiometer (280-400 nm, $0.5 \mathrm{~nm}$ resolution). The field sites were chosen to approximate as closely as possible a straight ice edge separating a high albedo surface (ice/snow) from a low albedo surface (water) (Figure 1).

The transects over the ice covered by snow on 6 days and water transects on 3 days are presented. Usually, a Biometer and the Macam were the fixed instruments at the ice edge, except when simultaneous ice and water transects were taken, in which case only the Macam was placed at the ice edge. All irradiance values were converted into ratios with respect to the instrument at the ice edge. At each site along a transect, readings were taken at one-minute intervals for at least 8 minutes and an average ratio calculated. On several occasions measurements of UV albedo were conducted either at the ice edge or some distance from it. 


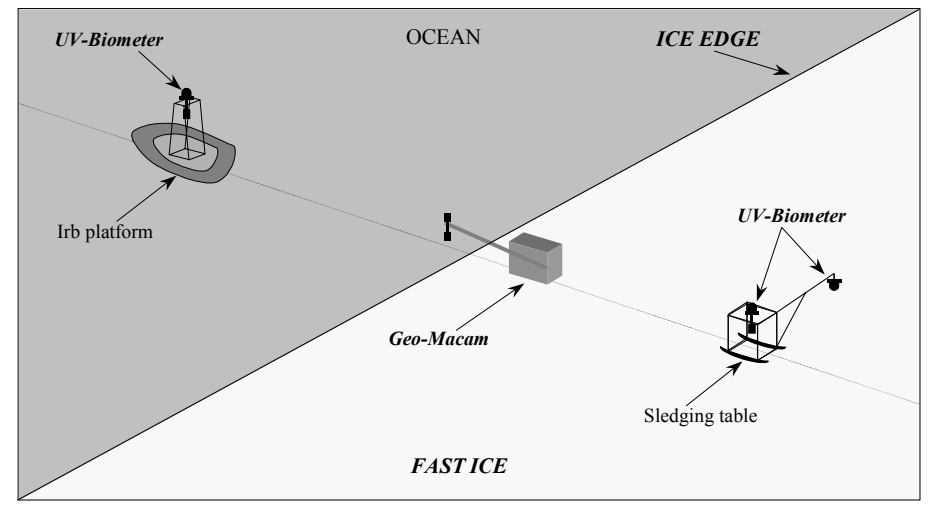

Fig. 1. Schematic diagram representing the field arrangements during the transcect measurements ${ }^{14}$.

\subsection{Radiation Measurements at Neumayer Station}

To measure spectral irradiance, radiance and albedo the spectroradiometer of the Institute of Meteorology and Climatology (IMUK) of the University of Hannover has been deployed. The IMUK spectroradiometer is capable of covering the spectral region from 280 to $1050 \mathrm{~nm}$. Prior to the Antarctic campaign, the IMUK spectroradiometer has achieved the internationally recognised standards of the Network for the Detection of Atmospheric Composition Change (NDACC, formerly: Network for the detection of stratospheric change) ${ }^{18}$.

As only one spectroradiometer was available to measure three different radiation parameters, spectral radiance and spectral albedo have only been measured on selected days with cloudless sky or overcast conditions with stratiform clouds. Spectral irradiance has been measured continuously at all other times. In total, 2725 spectra of irradiance were measured on 86 days. To determine the spectral albedo, 1026 spectra of up- and downwelling irradiance with varying wavelength range were measured on 12 days. 336 spectra of radiance have been collected on 20 days. To control the data quality of the spectral radiation parameter, regular checks of the radiometric and wavelength stability have been performed $^{15,19}$.

\section{MODELLING OF ANTARCTIC RADIATION PARAMETERES}

Two different radiative transfer models have been employed to support the analysis of the measured radiation parameters. One is the freely available library for radiative transfer calculations libRadtran ${ }^{20}$, the other is the 3-D Monte Carlo UVRTIS Code ${ }^{13}$.

\section{1 libRadtran}

To experimentally investigate the effect different albedo surfaces on the downwelling radiation parameters, it is vital to perform measurements with equal atmospheric situations. All influencing parameters, such as solar zenith angle (SZA), cloud cover, total ozone column and altitude should be the same, but the albedo should differ. As this is basically impossible, radiative transfer calculations with libRadtran are used to imitate the situation during the actual measurement, but with a different albedo.

The radiative transfer solver used in this method is a one-dimensional discrete ordinate method ${ }^{21}$. The atmospheric input parameters comprise

- the SZA dependent on wavelength according the scan time,

- the measured spectral snow albedo from the cloudless afternoon of 4 January 200422

- the total ozone column derived from the Total Ozone Mapping Spectrometer (TOMS; ftp://jwocky.gsfc.nasa.gov/pub/eptoms/data/overpass/OVP323_ept.txt)

- no aerosols, and 
- subarctic atmospheric profiles.

\subsection{UVRTIS}

Downwelling radiation parameters in an inhomogeneous environment can best be modelled with a three-dimensional Monte Carlo Model. For this purpose the UVRTIS (UV Radiative Transfer over an Inhomogeneous Surface) model was developed $^{13}$. The model calculations are made in a plane-parallel, vertically inhomogeneous atmosphere over a given area which in this case, is assumed to be $100 \times 100 \mathrm{~km}^{2}$. Half of this area is set to be an open ocean, while the other half is considered to be a snow-covered ice floe. The photons' trajectories are followed in three-dimensional (3-D) space to define the surface UV irradiance on a two-dimensional (2-D) surface grid. Both molecular scattering and ozone absorption are considered. Resulting spectral irradiances $\left(\mathrm{mW} \mathrm{m}^{-2} \mathrm{~nm}^{-1}\right)$ are computed at 70 wavelengths in steps of 1 $\mathrm{nm}$ from 296 to $330 \mathrm{~nm}$ and in steps of $2 \mathrm{~nm}$ at longer wavelengths up to $400 \mathrm{~nm}$. Finally, biologically effective ultraviolet irradiances (or erythemal doses in $\mathrm{J} \mathrm{m}^{-2}$ ) at each point of the surface grid are calculated by integrating the product of the spectral irradiances and the CIE action spectrum for erythema in human $\operatorname{skin}^{23}$ over the whole wavelengths range. The downwelling spectral irradiances are calculated as a function of a distance from the ice edge. By changing initial parameters like downwelling irradiance, solar zenith angle, surface reflectivity and the distribution of the surface albedo, the sensitivity of the simulation to these changes can be examined.

\section{RESULTS}

\subsection{Spectral Albedo}

To illustrate the spectral dependence of albedo, the mean spectral albedo measured on three different days during the campaign at Neumayer is shown in Figure 2. In Figure 3 the daily mean spectral albedo is shown for a limited

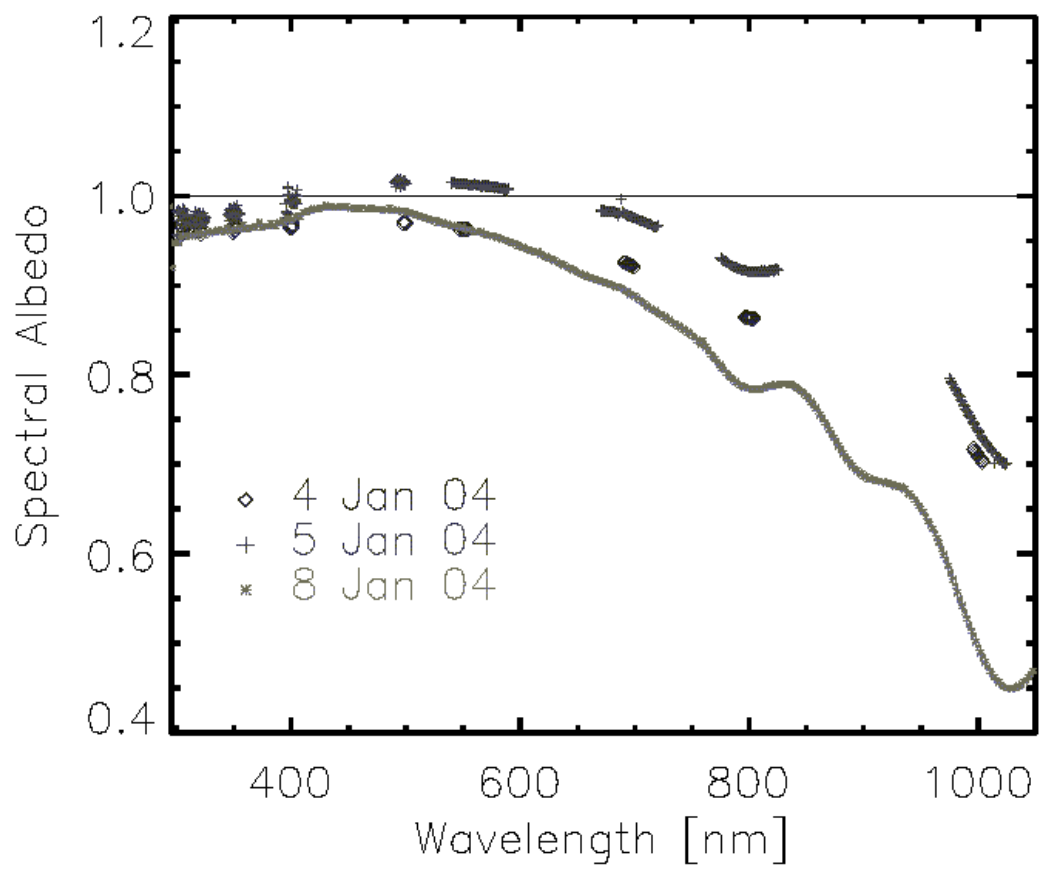

Fig. 2. Daily mean spectral albedo measured at Neumayer on three selected days. The maximum value is reached at about $500 \mathrm{~nm}$. The albedo decreases slightly towards shorter wavelengths. The decrease in albedo for longer wavelengths becomes more pronounced in the infrared for wavelengths greater than $800 \mathrm{~nm}^{22}$. 


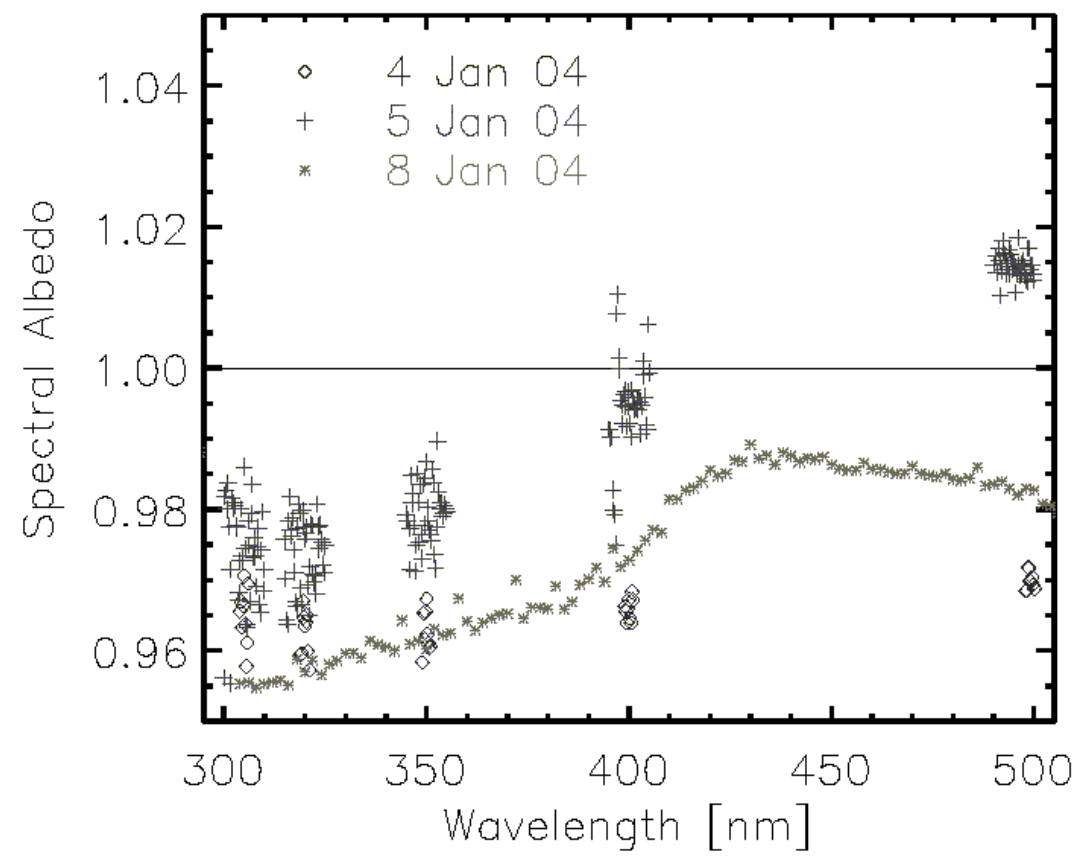

Fig. 3. Same as Figure 2, but the wavelength range is limited (295 to $505 \mathrm{~nm}$ ). On 5 Jan 04, the albedo is larger than unity with 1.015 at $500 \mathrm{~nm}$, which is an effect of direct incidence of solar radiation ${ }^{22}$.

wavelength range (295 to $500 \mathrm{~nm}$ ) to emphasise the region where the albedo is nearly unity. The albedo in the UV is between 0.95 and 0.99 . It increases slightly with increasing wavelength to reach its maximum around 0.99 at $430 \mathrm{~nm}$ on most days (Figure 3). 5 January 2004 presents an exception with the mean albedo reaching a maximum of 1.01 at 500 $\mathrm{nm}$. The albedo remains high up to $800 \mathrm{~nm}$ in the visible. The decline of the slope for increasing wavelengths is steeper for wavelengths longer than $800 \mathrm{~nm}$ (Figure 2). At $1000 \mathrm{~nm}$, the observed albedo ranges between 0.45 and 0.75 . It cannot be decided which albedo spectrum is highest. This depends on wavelength as the spectra cross each other. 

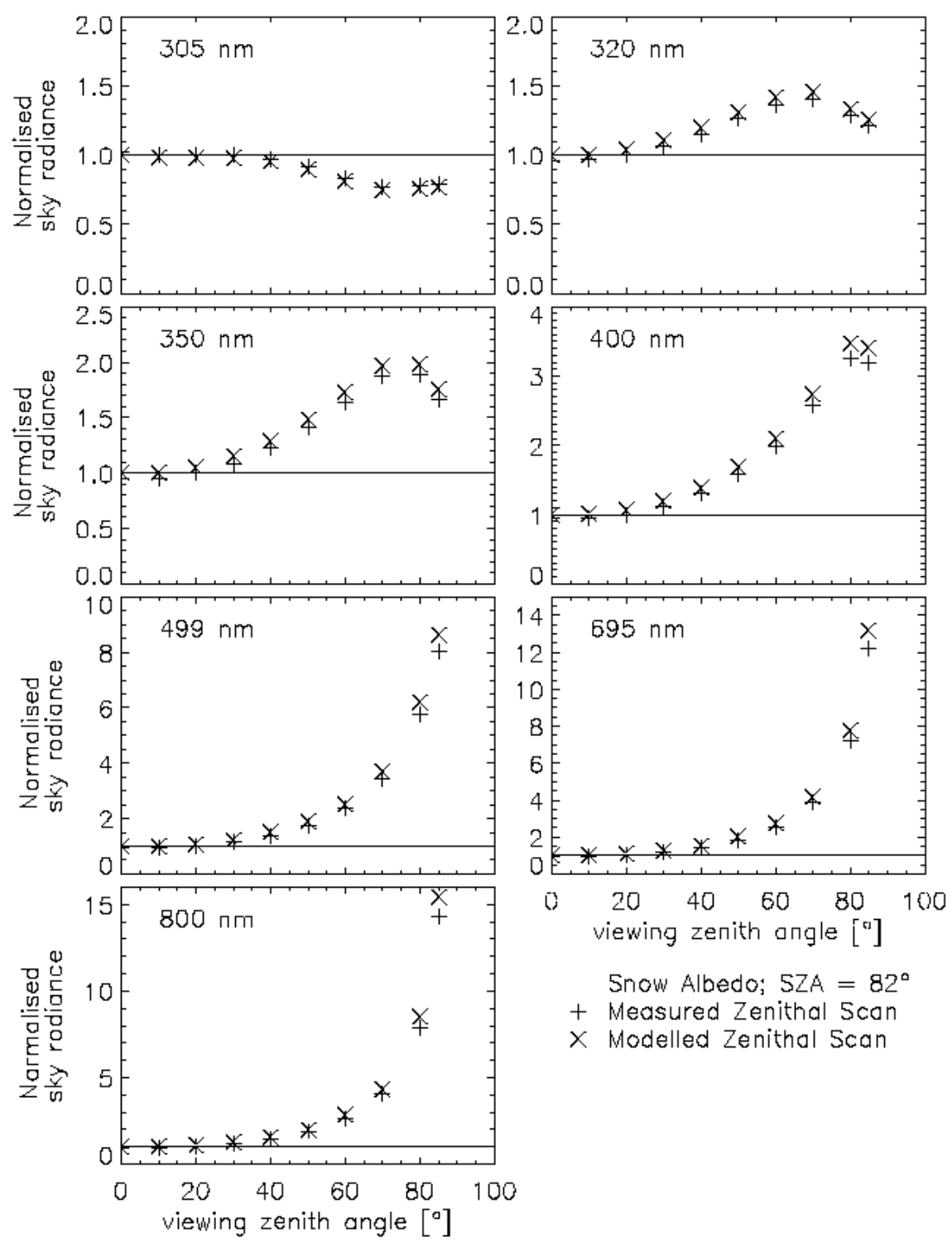

Fig. 4. Measured and modelled zenithal scans of radiance for different wavelengths. Zenithal scans of radiance have been measured over a snow surface and high SZA $\left(82^{\circ}\right)$ in Antarctica. The modelled radiance is slightly higher, especially for large viewing zenith angles. Horizon brightening is seen for all wavelengths in the visible. In the $\mathrm{UV}$, the maximum radiance occurs for different viewing zenith angles ${ }^{25}$.

In theory such an albedo larger than one is impossible. On cloudless occasions the reflectance of the snow surface has a larger directional component as during overcast situations ${ }^{24}$. The situation on 5 January 2004 was not completely cloud free, but an opaque cirrus layer covered the sky, thus there was a direct component of the incident radiation. In conjunction with a mislevelled sensor this could lead to an albedo of larger than one.

\subsection{Spectral Radiance}

Diffuse sky radiance has also been measured during the Antarctic campaign to investigate the wavelength dependence on the directional distribution of the diffuse sky radiation. Figure 4 shows zenithal scans of radiance for different wavelengths measured at Neumayer during the evening of 9 February 2004, thus with high SZA. The zenithal scan was measured in the principal plane opposite the sun $\left(\mathrm{SAA}+180^{\circ}\right)$ under a cloudless sky. In addition, this situation has been 
modelled, which is also shown. Measured as well as modelled radiance has been normalised to the zenith. For the model calculations libRadtran ${ }^{20}$ has been used. The input parameters have already been explained in Section 3.1.

A feature called horizon brightening is observed at all wavelengths except for $305 \mathrm{~nm}$. The term horizon brightening describes the radiance being higher at the horizon compared to the zenith. In general, horizon brightening increases the longer the wavelength. At short wavelengths in the UVB multiple scattering of diffuse irradiance occurs uniformly across the sky due to the strong wavelength dependence of Rayleigh scattering. For radiation with long wavelengths, multiple scattering can only be produced by longer paths through the atmosphere, which is the case for directions close to the horizon. Therefore, inhomogeneous radiance distributions across the sky are better seen the longer the wavelength.

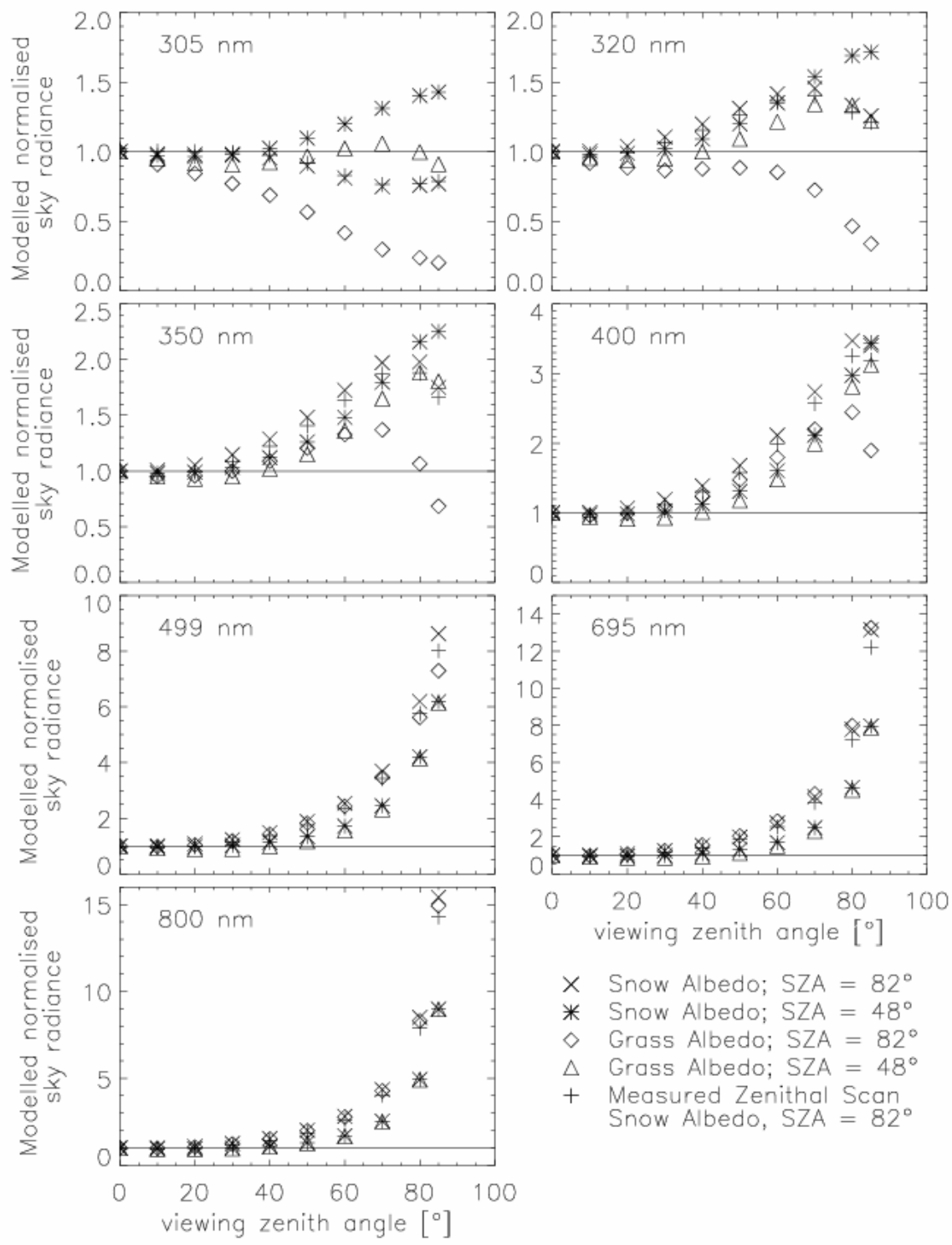

Fig. 5. Modelled zenithal scans of radiance for a high SZA of $82^{\circ}$ and a low SZA of $48^{\circ}$ over grass and a snow covered surface. For all cases, horizon brightening is seen for all wavelengths in the visible. In the UV, horizon brightening is only observed for the case with snow albedo and SZA of $82^{\circ 25}$.

In order to assess the influence of a snow surface compared to a grass surface, zenithal scans of radiance at different wavelengths have been modelled for a varying surface albedo (Figure 5). The zenithal scan over a snow covered surface 
with a high SZA of $82^{\circ}$ represents the situation on 9 February 2004 around 20:15 UTC, which has also been measured (Figure 3). The two cases representing the radiance over a grass surface only differ in input albedo ${ }^{25}$. In addition, both albedo situations have been modelled for a low SZA of $48^{\circ}$. The input albedo for snow and grass in dependence of wavelength is shown in Table 1.

\subsubsection{UV}

For all UV wavelengths, horizon brightening is observed for the case with snow albedo and SZA of $48^{\circ}$. At $400 \mathrm{~nm}$, radiance with a viewing zenith angle (VZA) of $86^{\circ}$ exceeds the zenith radiance by a factor of 3.5.For grass albedo and SZA of $82^{\circ}$ the radiance decreases for increasing VZA for 305 and $320 \mathrm{~nm}$. At 350 and $400 \mathrm{~nm}$, the radiance increases up to a VZA of $70^{\circ}$, and then decreases again. This maximal radiance at a VZA between $70^{\circ}$ and $80^{\circ}$ is also observed for the grass albedo at a SZA $=48^{\circ}$ at 305,320 and $350 \mathrm{~nm}$ as well as for the snow albedo and a SZA of $82^{\circ}$ at 320,350 and $400 \mathrm{~nm}$.

Table 1. Albedo of snow and grass for different wavelengths. The albedo of grass is taken from Feister and Grewe $(1995)^{26}$ and the albedo of snow was measured at Neumayer on 4 January $2004^{15}$.

\begin{tabular}{|l|l|l|}
\hline Wavelength [nm] & Albedo of grass & Albedo of snow \\
\hline 305 & 0.017 & 0.971 \\
\hline 320 & 0.017 & 0.961 \\
\hline 350 & 0.018 & 0.966 \\
\hline 400 & 0.022 & 0.967 \\
\hline 499 & 0.035 & 0.965 \\
\hline 550 & 0.089 & 0.962 \\
\hline 695 & 0.040 & 0.900 \\
\hline 800 & 0.587 & 0.830 \\
\hline
\end{tabular}

\subsubsection{Visible}

Horizon brightening is observed for all cases. For both surface types, it is larger the larger the SZA. The maximum horizon brightening is observed over a snow surface at $800 \mathrm{~nm}$ with a factor of 15.5 for a SZA of $82^{\circ}$. At $695 \mathrm{~nm}$ and a SZA of $82^{\circ}$, horizon brightening for grass is slightly higher than for snow. At a SZA of $48^{\circ}$ horizon brightening does not show a strong dependence on the type of surface.

\subsection{Measurements of UV irradiance enhancement near an ice/water boundary}

Table 2 summarises the broadband albedo measurements taken with two UV-Biometers during the summer campaign at Davis Station (see Section 2.1). The ice edge albedos were measured at a distance of approximately $1 \mathrm{~m}$ from the ice edge. On 21 Nov 97 an albedo measurement was also taken $2.5 \mathrm{~km}$ from the ice edge. Albedo transects were performed on two occasions (4 Dec 97, 15 Dec 97). The upwelling and downwelling irradiances were measured at each site along the transect for approximately 10 minutes and a mean albedo was calculated for the site. Table 2 presents the albedo at the ice edge and the albedo averaged over the whole transect for these two days.

Table 2. Broadand UV albedo measurements at Davis Station ${ }^{14}$

\begin{tabular}{|l|l|l|l|}
\hline Date & Time (TST) & Location & Albedo \\
\hline 10 Nov 97 & $11: 25-12: 53$ & ice edge & 0.95 \\
\hline 12 Nov 97 & $12: 21-12: 44$ & ice edge & 0.97 \\
\hline 21 Nov 97 & $9: 58-10: 32$ & ice edge & 0.84 \\
& $14: 02-14: 10$ & $+2.5 \mathrm{~km}$ & 0.87 \\
\hline 4 Dec 97 & $11: 22-11: 30$ & ice edge & 0.81 \\
& $11: 22-13: 42$ & mean transect & 0.76 \\
\hline 15 Dec 97 & $12: 52-13: 02$ & ice edge & 0.48 \\
& $12: 52-14: 57$ & mean transect & 0.57 \\
\hline
\end{tabular}


Results show very high albedos at the ice edge during the early part of the field program and a gradual decline as the spring progressed. On 21 Nov 97 and 4 Dec 97 the albedos away from the ice edge were within 10\% of the corresponding ice edge values, although all the albedo values were considerably lower than in early November. On 15 Dec 97 the albedo at the ice edge was approximately halved in comparison to the values measured on 10 Nov 97 and 12 Nov 97. The observed reduction of albedo can be attributed to aging of the snow, thinning of the snow cover, and greater amounts of dust in the snow.

Figure 6 presents the normalised irradiance ratios for four days (18 Nov 97, 21 Nov 97, 8 Dec 97, 9 Dec 97) some cloudless and some with cirrus or altocumulus clouds of $1 / 8$ or less, which were equated to clear sky conditions. The four ice transects are quite similar, as are the four water transects, although the water transects were taken on only two separate days. The pattern shows a monotonic increase (decrease) of the ratios over ice (water) at greater distances from the ice edge. Moreover the ratios appear to approach limiting values at distances greater than $2 \mathrm{~km}$ from the ice edge. Comparing the irradiance at $-2.5 \mathrm{~km}$ with the irradiance at $+2.5 \mathrm{~km}$, an overall irradiance enhancement of $10 \%$ is obtained in the snow environment.

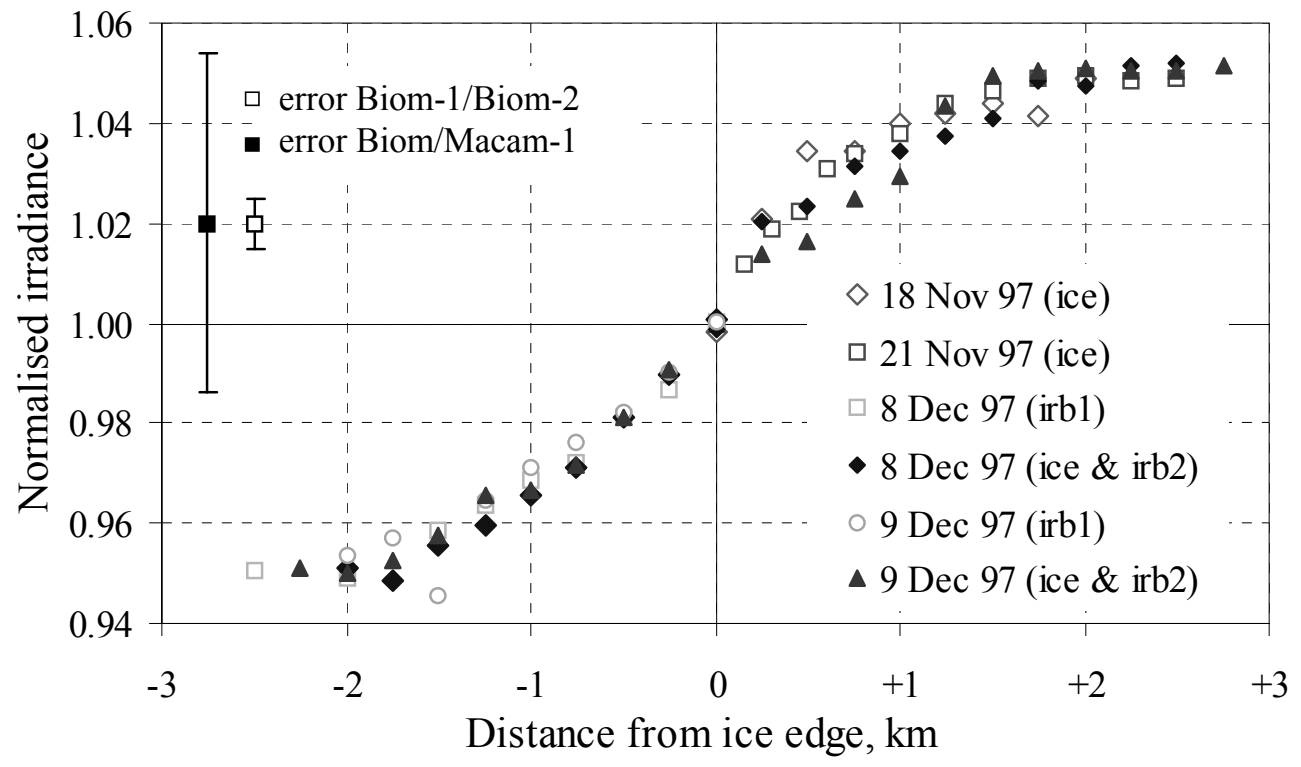

Fig. 6. Normalised irradiance ratios for transects conducted on cloudless days as a distance from the ice edge. Open symbols are ratios based on two UV-Biometers; closed symbols are ratios based on Macam and a UVBiometer. Error bars are estimated errors $(1 \sigma)$ in the ratios ${ }^{14}$. 


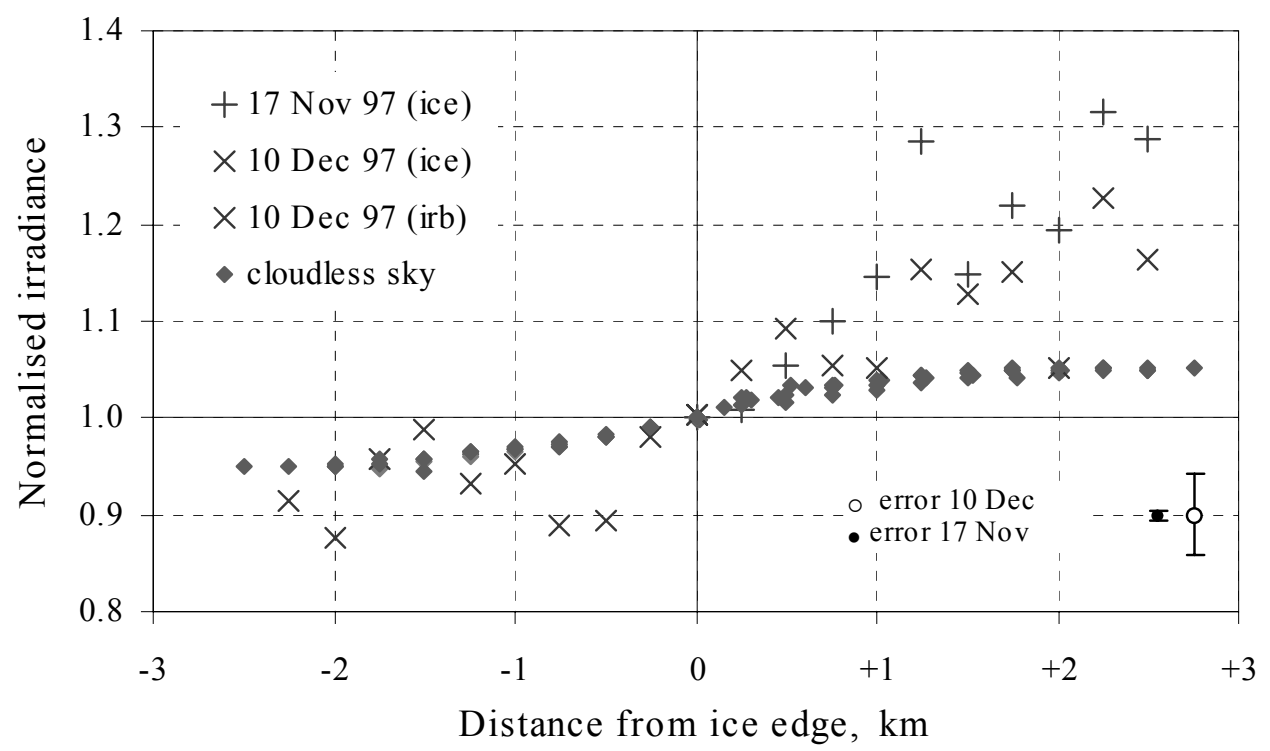

Fig. 7. Normalised irradiance ratios for transects conducted on cloudless and overcast days as a distance from the ice edge. Crosses are ratios on overcast days; closed symbols are ratios for cloudless days (as described in Figure 6.). Error bars represent estimated errors $(1 \sigma)$ in the ratios for two UV-Biometers (17 Nov 97) and Macam/Biometer combination (10 Dec 97) $)^{14}$.

Normalised irradiance ratios for both cloudless and overcast conditions are presented in Figure 7. In comparison to the cloudless data, a much larger scatter can be noticed for overcast days (crosses) over both ice and water, presumably due to variability in cloud optical depth, cloud base height, cloud morphology and coverage. Figure 7 clearly shows that the normalised irradiance ratios for overcast conditions changed more rapidly with distance from the ice edge than on cloudless days. This behaviour is most obvious over ice where ratios are $\sim 1.30$ at distances of $2.5 \mathrm{~km}$ from the ice edge. Even in overcast conditions there still existed much spatial and temporal regional variability of cloudiness, which contributed to the scatter in the irradiance ratios by virtue of multiple reflection processes between the snow surface and cloud base. 

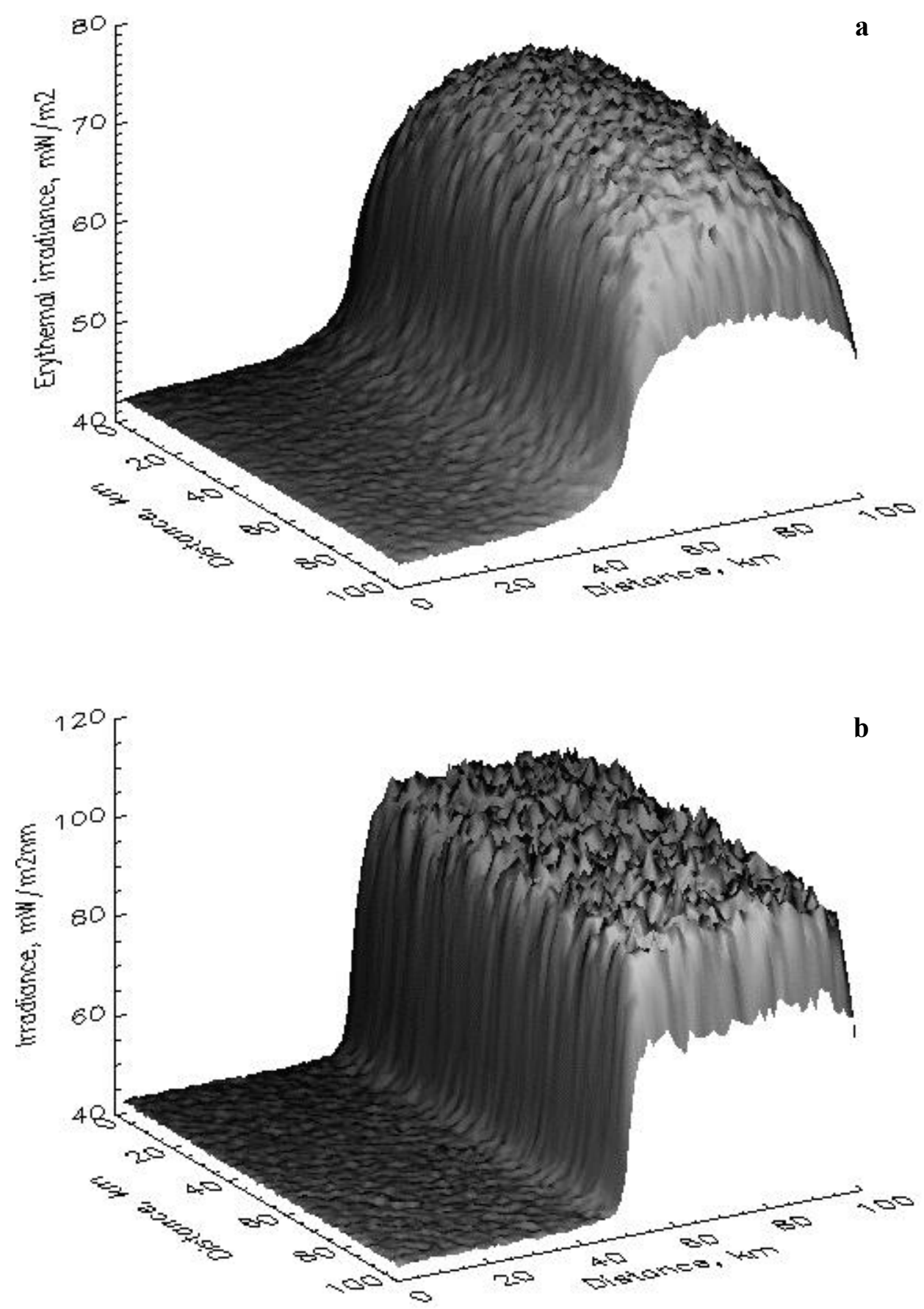

Fig. 8. Examples of the UVRTIS model 3-D simulations showing a) clear sky erythemal and b) overcast sky at $312 \mathrm{~nm}$ irradiance distributions at the ground. Surface grid is divided in half water (albedo $=0.05$ ) and half snow-covered ice (albedo $=0.9$ ). Calculations are done with $\mathrm{TOC}=350 \mathrm{DU}$ and $\mathrm{SZA}=60^{\circ}$ and for overcast sky $\tau_{\text {cloud }}=15, \mathrm{~h}_{\text {cloud }}=1 \mathrm{~km}$ and $\tau_{\text {cloud }}=0.7^{13}$. 


\subsection{Modelling of UV Irradiance enhancement near an ice/water boundary with UVRTIS}

Two examples of the model output are given in Figure 8 for a model's surface grid consisting of one half snow-covered ice and the other half ocean. Although the magnitude of change in the irradiance levels differs between water and snow, it is possible to observe a common feature in both plots. The UV irradiance decreases uniformly close to the grid edges because in each grid cell there are initially 103 incoming photons, while there are no incoming photons reaching the ground outside the grid. The closer a grid cell is to the edge of the grid, the less photons enter the cell to undergo surface reflections. This is called the edge effect hereafter and is more noticeable over the snow-covered surface than over the water, due to water's lower albedo.

Since the edge effect is mainly confined to $20 \mathrm{~km}$ on each boundary, the study area was deliberately made large enough so that the edges could be 'cut off' to leave a central area unaffected by the edge problem. The model was run over an area of $100 \times 100 \mathrm{~km}^{2}$, but only an inner area of $60 \times 60 \mathrm{~km}^{2}$ is examined during the data analysis.

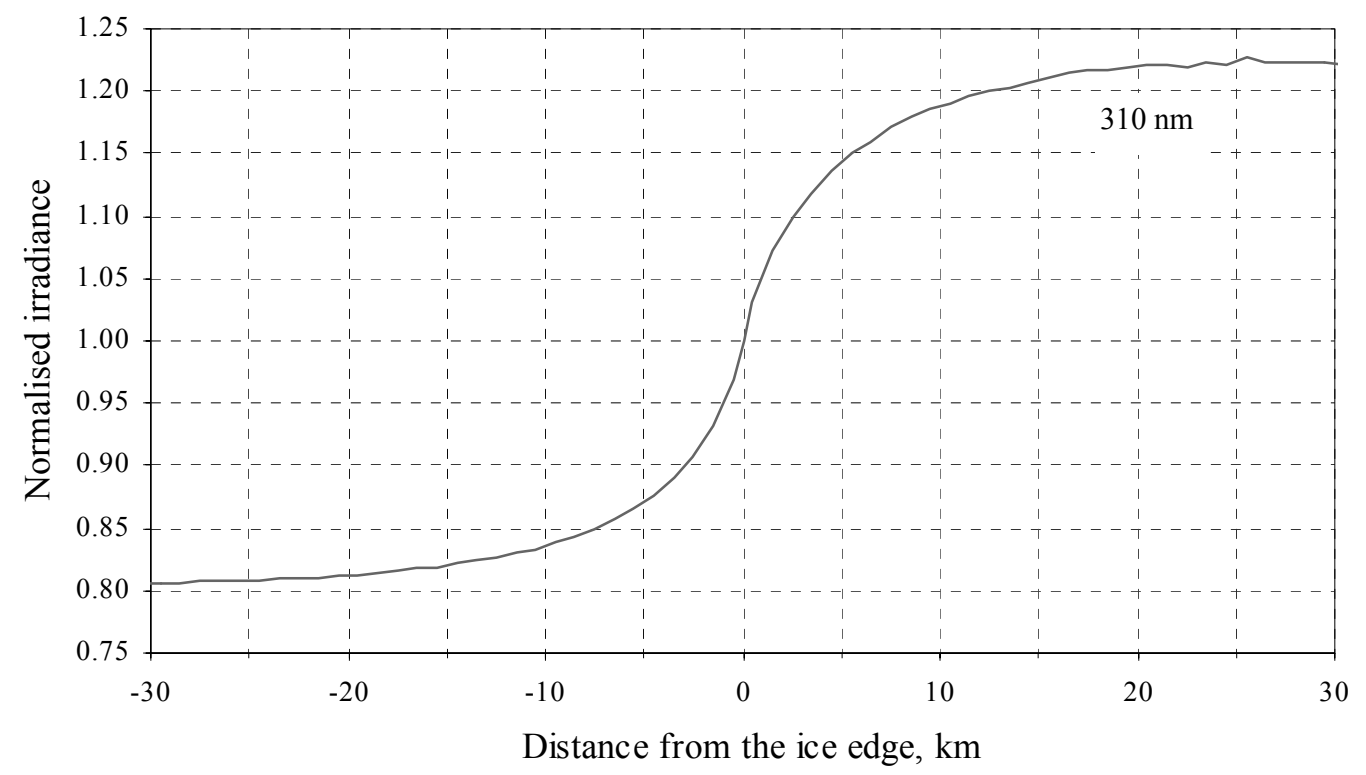

Fig. 9. Clear sky irradiance at $310 \mathrm{~nm}$ normalised to the value at the ice edge and plotted as a function of distance from the ice edge. Calculations are done with $\mathrm{TOC}=350 \mathrm{DU}, \mathrm{SZA}=60^{\circ}$ for $\alpha$ snow $=0.9$ and $\alpha$ water $=0.05^{13}$.

Figure 9 shows the normalised irradiance calculated for cloudless sky conditions at a wavelength of $310 \mathrm{~nm}$. The pattern shows a monotonic increase (decrease) of the enhancement over snow (water) at greater distances from the ice edge. The relative changes in irradiance are about $24 \%$ and $23 \%$ over the water and snow-covered surfaces respectively. The shape of the curve is reasonably symmetric relative to the ice/water boundary, and the normalised irradiances approach their limiting values at distances between 15 and $20 \mathrm{~km}$ from the ice edge on both sides. The total relative enhancement at 310 $\mathrm{nm}$ from water to snow-covered ice is significant and is about $52 \%$.

This study demonstrated that the UV irradiance at a given point is strongly controlled by the albedos of the far surroundings, with important contributions from areas more than 50 kilometers away from the observation site. A few percent of the enhancement can still be contributed from these far off regions.

\section{DISCUSSION}

The results of spectral radiance and irradiance measurements performed in Antarctica in combination with a 3-D modelling study show that the surface albedo has a great influence on the downwelling radiation parameters. This is mainly due to its large value which is nearly one in the UV and up to $550 \mathrm{~nm}$. Almost all incident radiation is reflected back yielding the possibility of multiple reflection and back scattering processes between the surface and the atmosphere. 
Two effects are detected in response to a high surface albedo. One is the alteration of the spatial distribution of sky radiance. Radiation from directions close to the horizon is more enhanced than from other directions. This effect becomes stronger with increasing wavelength. The other is the enhancement of irradiance due to a snow covered surface as well as in the surroundings of the measurement site. A region as far as $50 \mathrm{~km}$ away from the measuring site can still significantly contribute to the enhancement of irradiance, as predicted by earlier model studies.

Both effects have a common explanation: multiple reflections and scattering processes between the surface and the atmosphere. Thus, two factors have to be given to observe these features. One is the just mentioned high atmospheric reflectance. The other is the high surface albedo. The atmospheric reflectance is highest around $320 \mathrm{~nm}^{8}$. The surface albedo is maximal over a snow covered ground in the spectral region from the UV up to $550 \mathrm{~nm}^{22}$.

Experimentally, the described effects can be measured in the Antarctica because there are vast areas of homogeneous ice regions and clear boundaries between ice and open water. However, the results gained in the Antarctic region can be also applied to the Arctic where climate change is already a proven fact $^{27}$ : temperatures are increasing above the average global rate, sea ice thinning and retreat is observed. Thus, the surface albedo will decrease drastically. The positive icealbedo feedback is induced. Similar effects are observed in the area of the Antarctic Peninsular.

The changes in the radiation environment are the driving force for a lot of effects of climate change and therefore need further analysis. Experimental investigations are a necessary tool to prove model predictions. Experimental evidence can also be incorporated in the improvement in model parameterisations describing the climate system.

\section{CONCLUSION}

Experimental evidence has been given that the radiation field is altered by a highly reflective snow surface compared to a surface with low reflectivity. These findings are shown for the spatial distribution of sky radiance as well as the effect of irradiance enhancement. However, due to the limited periods when the radiation measurements could be conducted, only a few atmospheric situations have been encountered. To gain statistically significant results, or to even facilitate statistic analyses, more high quality measurements of radiation parameters over a highly reflective surface need to be performed. In addition we have shown that reliable predictions require a careful treatment of the spectral analysis, both experimentally and theoretically.

\section{Acknowledgements}

This work was supported by ASAC grant 2210, Antarctic CRC, and ANARE in Australia and by DFG in Germany. We especially thank the Alfred-Wegener-Insitute for Polar and Marine Research for their logistic and scientific support.

\section{REFERENCES}

1. Schmidt, T. and König-Langlo, G., Radiation Measurements at the German Antarctic Station Neumayer 1982-1992, Reports on Polar Research, No. 146, 66pp., Bremerhaven, Germany, 1994

2. Vaughan, D. G., Marshall, G. J., Connolley, W. M., King, J. C., Mulvaney, R., Devil in the Detail, Science, 293, 5536, 1777-1779, 2001

3. Giorgi, F., Hewitson B., Christensen, J., Hulme M., von Storch, P., Whetton, P., Jones, R., Mearns, L.,Fu, C., Regional Climate Information - Evaluation and Projections, Chapter 10 of Climate Change 2001: The Scientific Basis. Contribution of Working Group I to the Third Assessment Report of the Intergovernmental Panel on Climate Change, Houghton, J. T., Ding, Y., Griggs, D. J., Noguer, M., van der Linden, P. J., Dai, X., Maskell, K., Johnson, C. A. (Eds.), Cambridge University Press, Cambridge, United Kingdom and New York, NY, USA, 583-638, 2001

4. Grenfell, T.C., Warren, S.G., Mullen, P.C., Reflection of solar radiation by the Antarctic snow surface at ultraviolet, visible and near-infrared wavelengths, J. Geophys. Res., 99, D9, 18669-18694, 1994

5. McKenzie, R.L., K.J. Paulin, and S. Madronich, Effects of snow cover on UV irradiance and surface albedo: A case study, J. Geophys. Res. 103, 28785-28792, 1998.

6. Kylling, A., A. Dahlback, and B. Mayer, The effect of clouds and surface albedo on UV irradiances at a high latitude site, Geophys. Res. Lett., 27, 1411-1414, 2000

7. Weihs, P., S. Simic, W. Laube, W. Mikielewicz, G. Rengarajan, and M. Mandl, Albedo influences on surface UV irradiance at the Sonnblick high mountain Observatory (3106 m altitude), J. Appl. Meteorol., 38, 1599-1610, 1999 
8. Lenoble, J., Modelling of the influence of snow reflectance on ultraviolet irradiance for cloudless sky, Appl. Opt., 37, 2441-2447, 1998

9. Nichol, S.E., Pfister, G., Bodeker, G.E., McKenzie, R.L., Wood, S., Bernhard, G., Moderation of Cloud Reduction of UV in the Antarctic Due to High Surface Albedo, J. of Appl. Met., 42, 1174-1183, 2003

10. Degünther, M., R. Meerkötter, A. Albold, and G. Seckmeyer, Case study on the influence of inhomogeneous surface albedo on UV irradiance, Geophys. Res. Lett., 25, 3587-3590, 1998

11. Lenoble, J., Influence of the environment reflectance on the ultraviolet zenith radiance for cloudless sky, Appl. Opt., 39, 42474254,2000

12. Kylling, A., and B. Mayer, Ultraviolet radiation in partly snow covered terrain: Observations and three-dimensional simulations, Geophys. Res. Lett., 28, 3665-3668, 2001

13. Smolskaia, I., Effect of inhomogeneous surface albedo on UV radiation in the Antarctic environment, PhD thesis, University of Tasmania, Hobart, Australia, 2001

14. Smolskaia, I., M. Numez, and K. Michael, Measurements of erythemal irradiance near Davis station, Antarctica: Effect of inhomogeneous surface albedo, Geophys. Res. Lett., 26, 1381-1384, 1999

15. Wuttke, S., Radiation Conditions in an Antarctic Environment, Reports on Polar and Marine Research, No. 514, Bremerhaven, Germany, 140 pp., 2005

16. Mayer, B., and M. Degünther, Comments on " Measurements of erythemal irradiance near Davis Station, Antarctica: Effect of inhomogeneous surface albedo", Geophys. Res. Lett.,27, 3489-3490, 2000

17. Macam Photometrics., Macam Spectroradiometer model SR9910 Operating Guide, 41 pp., Livingston, UK, 1996

18. Wuttke, S., Bernhard, G., Ehramjian, J., McKenzie, R., Johnston, P., O'Neill, M., Seckmeyer, G., New spectroradiometers complying with the NDSC standards, J. Atmos. Oceanic Technol., 23, 241-251, 2006

19. Wuttke, S., Seckmeyer, G., Schrems, O., G. König-Langlo, Radiation Measurements at the German Antarctic Neumayer Station, in Ultraviolet Ground and Space-Based Measurements, Models and Effects V, Bernhard, G. and Slusser, J. R. and Herman, J. R. and Gao, W. (Eds.), Spie Proceedings Series 5886, Bellingham, Washington, D.C., 588608-1 - 588608-10, 2005

20. Mayer, B. and Kylling, A., Technical note: The libRadtran software package for radiative transfer calculations - description and examples of use, Atmos. Chem. Phys. Discuss., 5, 1855-1877, 2005

21. Stamnes, K., Tsay, S. C., Wiscombe, W., Jayaweera, K., A numerically stable algorithm for discrete-ordinate-method radiative transfer in multiple scattering and emitting layered media, Appl. Optics, 27, 2502-2509, 1988

22. Wuttke, S., Seckmeyer, G., König-Langlo, Measurements of Spectral Snow Albedo at Neumayer, Antarctica, Annales Geophysicae, 24, 7-21, 2006

23. McKinlay, A.F., and B.L. Diffey, A reference action spectrum for ultraviolet induced erythema in human skin, CIE-Journal, 6 (1), $17-22,1987$

24. Dirmhirn, I. and Eaton, F.D., Some Characteristics of the Albedo of Snow, J. Appl. Met., 14, 375-379, 1975

25. Wuttke, S. and Seckmeyer, G., Spectral Radiance and Sky Luminance in Antarctica: A Case Study, Theor. Appl. Climatol., 85, 131-148, 2006

26. Feister, U. and Grewe, R., Spectral Albedo Measurements in the UV and visible region over different types of surfaces, Photochem. Photobiol., 62, 4, 736-744, 1995

27. ACIA,.Arctic Climate Impact Assessment. Cambridge University Press, 1042p., http://www.acia.uaf.edu, 2005 